\title{
Schema in older adults: Does the schema mode model apply?
}

Background: The relevance of schema theory to psychopathology, in particular personality disorder, in younger adults is established. Investigations into the relevance of schema theory to older adults however is highly limited. Aims: To consider the relationship of schema modes to psychopathology in older adults and establish whether maladaptive schema modes are associated with unmet needs and that this relationship is mediated by the healthy adult mode of responding in this population. Methods: One hundred and four older adults were recruited from an established database. Participants completed questionnaires assessing psychopathology, schema modes (YAMI: Young-Atkinson Mode Inventory) and basic psychological needs (BPNS: Basic Psychological Needs Scale - autonomy, competence and relatedness). Ninety-four responses were included after applying exclusion criteria. Results: The healthy adult schema mode was found to be associated with reduced psychopathology, and maladaptive child modes (angry and vulnerable child) to increased psychopathology. The healthy adult schema mode mediated the relationship between maladaptive child modes and needs satisfaction. Conclusions: As predicted by schema theory, the presence of one of the maladaptive child modes makes it difficult for an older individual to have their needs met, but the presence of healthy adult mode works to support this process.

Key Words: schema theory, schema modes, basic psychological needs, schema therapy, older adults 


\section{Introduction}

Schema theory proposes that certain early and inflexible belief patterns, also known as Early Maladaptive Schemas (EMS), can develop in childhood and broadly lead to psychopathology (Young, 1990). These EMS are proposed to develop due to chronic unmet needs during childhood (Young, Klosko, \& Weishaar, 2003). Another important aspect of schema theory is the concept of schema modes (Young, 1990; Young et al., 2003), which are moment to moment states that reflect clusters of activated schemas and their associated thoughts, feelings and behaviours (Voderholzer et al., 2014). There are currently up to 18 proposed schema modes, within four categories; maladaptive child modes, maladaptive coping modes, maladaptive parent modes and the healthy modes, the latter comprising the Healthy Adult and Happy Child modes (Bamelis, Renner, Heidkamp, \& Arntz, 2011). It is proposed that maladaptive coping modes function to help people cope with the intense activated feelings that result from needs thwarting, but paradoxically make it harder for an individual to have their core emotional needs met. In contrast, it is purported the healthy adult mode more successfully works to have these needs met; the mode is concerned with the longer term need satisfaction of the individual (Young et al., 2003). Schema modes have been associated with various psychiatric disorders, including personality disorders (Bamelis et al., 2011; Johnston, Dorahy, Courtney, Bayles, \& O'Kane, 2009; Lobbestael, Arntz, \& Sieswerda, 2005; Lobbestael, van Vreeswijk, \& Arntz, 2008) and other disorders such as bulimia (Talbot, Smith, Tomkins, Brockman, \& Simpson, 2015), OCD (Basile, Tenore, Luppino, \& Mancino, 2017) and behaviour problems (van Wijk-Herbrink et al., 2018). Positive outcomes of schema therapy (e.g., Giesen-Bloo et al., 2006; Sempertegui, Karreman, Arntz, \& Bekker, 2013), which derives from schema theory, 


\section{Schema in older adults}

including with older people (Videler et al., 2017), provides support for the application of this theory to clinical populations.

A primary component of Young's (1990) schema theory is the importance of core emotional needs. Young et al. (2003) propose a set of core emotional needs that are universal to all individuals. The thwarting of the satisfaction of a specific need is considered likely to result in the development of a corresponding EMS, for example, a child that grows up in an environment with little safety is likely to develop a cognitive schema that says the 'world is dangerous'. Young and colleagues propose five core emotional needs; secure attachments to others, autonomy, competence and sense of identity, freedom to express valid needs and emotions, spontaneity and play, and realistic limits and self-control, that correspond to broad schema domains. More recently, it has been proposed that there are more specific core emotional needs that correspond to each of the EMS (Lockwood \& Perris, 2012).

Needs are a core component of many psychological theories and therapies, but are often not well-defined (Flanagan, 2010). One attempt to specify these needs is Deci and Ryan's (1985) self-determination theory. This theory proposes three basic psychological needs drive human motivation. These psychological needs are described as requirements that are universal and innate and that are essential to an individual's motivation and emotional wellbeing. These basic needs are competence, autonomy, and relatedness. Any thwarting of these needs is thought to lead to psychopathology and 'illbeing', while satisfaction of these needs will lead to healthy development and wellbeing. In a meta-analysis, $\mathrm{Ng}$ et al. (2012) found that higher levels of perceived competence, autonomy, and relatedness were associated with lower levels of depression and anxiety. Lower basic psychological needs satisfaction has been associated with suicidal behaviour (Britton, van Orden, Hirsch, \& Williams, 2014), depressive 


\section{Schema in older adults}

symptoms in chronic pain (Lu, Uysal, \& Teo, 2011), and post-partum depression (Gauthier, Guay, Senécal, \& Pierce, 2010). The present study therefore considers basic psychological needs as defined in self-determination theory to broadly correspond with Young's (1990) concept of core emotional needs, seeking to draw links between the two theories.

Young's schema theory proposes a relationship between schema modes and needs. It suggests that should individuals come to rely on certain maladaptive modes in order to express, or cope with need frustrations, these modes will ultimately prove to be self-defeating (Flanagan, 2010), maintaining further need frustration and forming a pattern of 'schema maintenance' (Young et al., 2003). For example, an individual may shift into the angry child mode, where the affect is angry and frustrated, much like a child having a tantrum (Young et al., 2003) in an attempt to have a core emotional need, such as attachment to others, met. Ultimately, however, the result of expressing high levels of anger may have the effect of pushing others away, fuelling further disconnect with others. Schema therapy aims to reduce overreliance on these maladaptive modes, and to open up the opportunity for healthier ways of coping, via the healthy adult mode (Young et al, 2003). Indeed, higher levels of healthy adult mode are generally associated with lower levels of psychopathology (Lobbestael et al., 2005). If the presence of the healthy adult mode allows the individual to have their core emotional needs met, it follows that the relationship between maladaptive coping modes and unmet core emotional needs would be mediated by the presence of the healthy adult mode. Despite the fact that there is a proposed link between modes and thwarted emotional needs in Young's schema theory, this link has not yet been studied empirically. 


\section{Schema in older adults}

The present study aimed for the first time to investigate the relationship between schema modes and psychopathology in older adults, proposing that higher levels of maladaptive child modes would be associated with higher levels of depression, anxiety, and disordered personality symptoms. Conversely, it was also expected that higher levels of healthy adult mode would be associated with lower levels of psychopathology. Further, the present study aimed to validate schema theory in older adults by testing whether the presence of maladaptive child modes leads to the individual being less able to have their core needs (autonomy, competence, and relatedness) met. It was hypothesised that this relationship would be mediated by the presence of higher levels of the healthy adult mode. Given the need not to overburden participants with too many items, only select maladaptive child modes were used in the present study. These maladaptive child modes were chosen because the development of these schema modes is thought to be a direct result of needs thwarting environments. They were considered to be the best representative of activated core schemas.

\section{Method}

The method for the current study is described in detail elsewhere (Phillips, Brockman, Bailey, \& Kneebone, 2017). It is part of research stream broadly considering schema theory in older people (Phillips et al., 2017). The study received ethics approval from the University of Technology Sydney Human Research Ethics Review Committee and reciprocal approval from the Human Research Ethics Committee of Western Sydney University (approvals 2015000482-24 and H11617 respectively). The authors abided by the Ethical Principles of Psychologists and Code of Conduct as set out by the APA http://www.apa.org/ethics/code/. 


\section{Schema in older adults}

\section{Measures}

The Young-Atkinson Mode Inventory (YAMI; Young, Atkinson, Arntz, Engels, \& Weishaar, 2005) comprises of 187 self-report items that investigate the presence of 10 different schema modes. To reduce the burden on participants, in the current study, only the questions referring to the vulnerable child, angry child, and healthy adult modes were given. Previous studies have found internal reliability of the YAMI to be acceptable (van Vreeswijk, et al., 2014), and Phillips et al. (2017) found schema modes to be closely associated with EMS in older adults supporting convergent validity. The Basic Psychological Needs Scale (BPNS; General version) assesses unmet needs (autonomy, competence and relatedness) (Deci \& Ryan, 2000; Gagné, 2003). The BPNS consists of 21 items, with higher scores on the scale indicating higher needs satisfaction. It's sub-scales and total score are internally consistent (Gagné 2003; Kashdan et al. 2009; Meyer et al. 2007; Niemiec et al. 2009; Wei et al. 2005) and validity is evident from sub-scale and total scores associations with psychosocial wellbeing (e.g., pro-social behavior, vitality, and happiness) and negative relationships to anxiety and depression (e.g., Gagné 2003; Meyer et al. 2007; Niemiec et al. 2009). The Geriatric Depression Scale (GDS; Yesavage et al., 1982) is a 30-item scale (yes/no format) designed to assess symptoms of depression in adults over the age of 60 years. The GDS is a reliable and valid measure of depression (Stiles \& McGarrahan, 1998).The Geriatric Anxiety Inventory (GAI; Pachana et al., 2006) is a self-report questionnaire with 20 items (agree/disagree format) measuring anxiety in adults over 60 years of age._It also has sound psychometric properties (Johnco, Knight, Tadic \& Wuthrich, 2015). The Germans' (Personality) Screener (Germans, van Heck, Masthoff, Trompenaars, \& Hodiamont, 2010), is a scale consisting of 10 items which have been adapted from the Structured Clinical Interview for DSM-IV Personality Disorders (SCID-II; First et al., 1995) and is designed to screen for personality disorders. It has 
been found to correctly classify $78 \%$ of adults as having a personality disorder (First et al. 1995).

\section{Procedure}

One hundred and four older adult participants were recruited from a pre-existing volunteer database (54 males and 50 females). Participants were given information about the study over the phone. If they consented to participate, they met with the researcher face-to-face and completed the questionnaire package. Participants data was included in the study if it was confirmed they were aged over 60 years of age, functioned independently and were free of significant cognitive impairment. The latter was determined by a score 81 or more (Hsieh et al., 2015) on the Adenbrookes Cognitive Examination, Third Edition (ACE-III; Hsieh, Schubert, Hoon, Mioshi, \& Hodges, 2013). Volunteers were reimbursed AUD\$20 for participating in the study.

\section{Statistical Analysis}

First, correlational analyses were conducted to investigate the relationship between the schema modes and measures of psychopathology, as well as the modes and basic psychological needs scores. A mediation analysis was then conducted to investigate the hypothesis that maladaptive schema modes lead to unmet needs in adulthood, and that this relationship is mediated by healthy adult mode. Two analyses were carried out, where the independent variable was first vulnerable child mode and then angry child mode, and the dependent variable was level of needs satisfaction (comprising autonomy, relatedness and competence). The mediator was the healthy adult mode. The hypothesized a-path was that as levels of vulnerable or angry child increase, levels of healthy adult mode would decrease. The hypothesized b-path was that the mediator, 


\section{Schema in older adults}

healthy adult mode, would predict higher levels of total needs satisfaction. The hypothesized c-path was that vulnerable and angry child mode would lead to lower levels of total needs satisfaction.

The present study used the PROCESS plug-in for SPSS (Hayes, 2013) in order to conduct bootstrapping analyses on the indirect path (ab-path). The indirect effect, that is the mediation effect, was estimated using nonparametric bootstrapping $(\mathrm{n}=10,000)$, in order to create a confidence interval for the indirect effect $(95 \% \mathrm{CI})$. All analyses were conducted using IBM SPSS Statistics package version 20.

\section{Results}

\section{Participants}

In total, 10 participants were removed from the sample due to a large proportion of missing responses, an incomplete ACE-III or failure to score above the cut-off on the ACE-III. This resulted in a final sample of 94 participants. The mean age of participants was 72.34 years $(S D=5.93$, Range 60-84) and 50\% were female. Around half had 12 years formal education or longer and for the majority (88\%) their first language was English. Sixty five percent were married or in a long-term relationship.

\section{Correlation analysis}

Pearson correlation coefficients $(r)$ were calculated between the schema modes and measures of psychopathology. As can be seen in Table 1, vulnerable child mode correlated positively with depression, anxiety and disordered personality and negatively with psychological needs in general, autonomy, competence, and relatedness. Angry child mode demonstrated positive correlations with depression, anxiety and disordered 


\section{Schema in older adults}

personality, and negative correlations with autonomy, competence and relatedness, as well as total needs. The healthy adult mode showed the opposite pattern, correlating negatively with depression, anxiety and disordered personality. As also evident in Table 1 higher levels of healthy adult mode were associated with higher levels of psychological needs being met in general as well as autonomy, competence and relatedness individually. All correlations were observed to be moderate to strong.

[Insert Table 1 about here]

\section{Mediation analysis}

As Figure 1 illustrates, vulnerable child mode was a significant predictor of healthy adult mode, where higher levels of vulnerable child predicted lower levels of healthy adult mode $(\beta=-0.20, \mathrm{SE}=0.05, p<0.01)$. Higher levels of healthy adult mode predicted higher total needs satisfaction $(\beta=.67, \mathrm{SE}=0.19, p<0.01)$. The direct effect between vulnerable child and total needs satisfaction was significant $(\beta=-0.53, S E=$ $0.09, p<0.01$ ). Non-parametric bootstrapping analyses (Hayes, 2013) indicated a significant indirect effect of vulnerable child mode on total needs satisfaction through the healthy adult mode $(a b=-0.13, B C a C I \mid[-0.29,-0.04])$. The mediator accounted for one fifth of the total effect, $P M=0.20$. As the direct effect was also significant, these results are consistent with partial mediation.

\section{[Insert Figure 1 about here]}

As Figure 2 illustrates, angry child mode was a significant predictor of healthy adult mode, where higher levels of angry child mode predicted lower levels of healthy adult mode $(\beta=-0.27, S E=0.09, p<0.01)$. The relationship between healthy adult mode and total needs satisfaction was also significant $(\beta=.78, S E=0.18, \mathrm{p}<0.01)$. Angry child 


\section{Schema in older adults}

was a significant negative predictor of total needs satisfaction $(\beta=-0.92, S E=0.16, \mathrm{p}<$ 0.01). Again, bootstrapped confidence intervals (Hayes, 2013), revealed a significant indirect effect for angry child mode on total needs satisfaction via the healthy adult mode, $a b=-0.21, B C a C I[-0.47,-0.05]$, again consistent with partial mediation. The mediator accounted for roughly one fifth of the total effect, $P M=0.19$.

[Insert Figure 2 about here]

\section{Discussion}

The present study aimed to investigate the applicability of schema mode theory to older adults. As predicted, higher levels of the vulnerable and angry child modes were associated with higher levels of psychopathology while higher levels of healthy adult mode were associated with lower levels of psychopathology. This is in line with findings in younger samples that the healthy adult mode is lowest in patients with psychopathology and personality disorders such as borderline personality disorder, and that higher levels of dysfunctional schema modes are associated with psychopathology (Arntz, Klokman, \& Sieswerda, 2005; Lobbestael et al., 2005). As additionally predicted by schema theory, the healthy adult mode was found to be associated with higher levels of autonomy, competence, and relatedness need satisfaction, and the vulnerable and angry child modes with lower needs satisfaction in these areas. This study provides the first empirical support for the hypothesized need-mode link using a psychometric measure of need satisfaction. By doing so it establishes a link between schema theory, and over 30 years of theory and research from the well-being literature that has culminated in Self-Determination Theory (Deci \& Ryan, 2000). The current study also provided further support for schema theory, finding that the relationship between maladaptive child modes (angry and vulnerable child mode) and needs 


\section{Schema in older adults}

satisfaction was partially mediated by the healthy adult mode. We interpret this in line with Schema Theory, that is there is an indelible link between emotional vulnerable and angry mood states and the experience of need satisfaction (or thwarting), and that this link is at least partially explained by the resulting presence of absence of the healthy adult mode. While these results are significant, they are also only relatively small (and partial), and there is substantial variance between core emotional schema modes and needs that is direct.

The results of the present study have possible implications for the application of schema theory, as well as schema therapy, in an older adult population. The mediation analysis supported the schema mode model, finding that the healthy adult mode mediates the relationship between two maladaptive child modes and needs satisfaction (Young et al., 2003) specifically in an older adult population. This implies that schema therapy, which aims to weaken maladaptive modes while also strengthening the adaptive (healthy adult) modes to facilitate core emotional need satisfaction (van Vreeswijk, Spinhoven, Eurelings-Bontekoe, \& Broersen, 2014; Young et al., 2003), may be effective in older adults. Previous research into schema therapy with older adults has found that maladaptive schema modes decrease and healthy adult mode increases between pre and post treatment (Videler, Rossi, Schoevaars, van der FeltzCornelis, \& van Alphen, 2014). It follows that specifically targeting schema modes in treatment of personality disorders with older adults may reduce symptoms of psychopathology and increase their needs satisfaction. As modes are thought to be present in all adults, not only those with personality disorders (van Genderen, Rijkeboer, \& Arntz, 2012), schema therapy may provide an appropriate modality for treating various other psychological disorders in this population. Future research should test this relationship in older adults receiving schema therapy. 


\section{Schema in older adults}

More broadly, this study also provided support for Young et al. (2003) schema theory. While this theory proposes that maladaptive schema modes maintain a sense of unmet core emotional needs, neither the needs themselves, nor the assertion that maladaptive modes are associated with lower needs satisfaction, has been empirically established. The present study demonstrated the predicted relationship. The study also provides a link between schema theory and self-determination theory (Deci \& Ryan, 2000). The three basic psychological needs can potentially be linked to the core emotional needs of schema theory. For example, the authors Lockwood and Perris (2012), have proposed that there is overlap between the connection and acceptance cluster of needs in schema theory and the relatedness need of self-determination theory.

As far as the authors of the present study are aware, this work is the first to specifically investigate schema theory in older adults with respect to psychopathology. It is also unique in its attempt to demonstrate that the healthy adult mode mediates the relationship between maladaptive child modes and needs satisfaction in any population, a key proposition of the theory. In terms of limitations, the study had a relatively small sample size and was cross-sectional thereby limiting conclusions of causality. In addition, several measures used in the study, namely the Basic Psychological Needs Scale, the Yami-Atkinson Mode Inventory, and the Germans' (Personality) screener have not been validated in an older adult sample. Our sample of data, however, demonstrates some initial validity for their use in an older adult sample. While the lack of clinical group, particularly a lack of a group with a diagnosed personality disorder, can be seen as a limitation, the sample recruited does indicate the relevance of the schema model to all older adults, not just those with these conditions. We would expect stronger findings in a clinical sample given maladaptive schema modes are hypothesised to be more common and prominent in people with personality disorders, 
In addition, only maladaptive child modes were investigated in the present study. Future research should expand on the modes studied in the current study to see if the schema mode model holds across all the hypothesised models.

These results lend further support to the use of schema therapy in older adults. Targeting the healthy adult mode and reducing the impact of maladaptive modes via therapy might allow older adults to have their needs met in areas such as autonomy, relatedness and competence. It also suggests that lowering maladaptive modes has the potential to reduce general psychopathology. Further research investigating the relevance of schema therapy and schema theory to older adults with psychopathology is warranted. Treatment studies of schema therapy that specifically target schema modes, are another potential direction for future research, and would support the ongoing development of protocols for schema therapy with older adults.

\section{Financial support}

This work was supported in part by the Australian Research Council under Discovery Project Grant [grant number DP130101420] to P. Bailey.

\section{Conflict of interest declaration}

We have no conflict of interest to declare with respect to this publication. 


\section{References}

Arntz, A., Klokman, J., \& Sieswerda, S. (2005). An experimental test of the schema mode model of borderline personality disorder. Journal of Behavior Therapy and Experimental Psychiatry, 36, 226-239. doi.org/10.1016/j.jbtep.2005.05.005.

Bamelis, L .L., Renner, F., Heidkamp, D., \& Arntz, A. (2011). Extended schema mode conceptualizations for specific personality disorders: An empirical study. Journal of Personality Disorders, 25, 41-58. doi:10.1521/pedi.2011.25.1.41.

Basile, B., Tenore, K., Luppino, O. I., \& Mancini, F. (2017). Schema therapy mode model applied to OCD. Clinical Neuropsychology, 14, 407-414.

Britton, P. C., Van Orden, K. A., Hirsch, J .K., \& Williams, G. C. (2014). Basic psychological needs, suicidal ideation, and risk for suicidal behavior in young adults. Suicide and Life-threatening Behavior, 44, 362-371. doi:10.1111/sltb.12074.

Deci, E.L., \& Ryan, R.M. (1985). Intrinsic motivation and self-determination in human behavior. Boston, MA: Springer. doi:10.1007/978-1-4899-2271-7.

Deci, E.L., \& Ryan, R.M. (2000). The" what" and" why" of goal pursuits: Human needs and the self-determination of behavior. Psychological Inquiry, 11, 227268. doi:10.1207/S15327965PLI1104_01.

First, M. B., Spitzer, R. L., Gibbon, M., Williams, J. B., Davies, M., Borus, J., ... \& Rounsaville, B. (1995). The structured clinical interview for DSM-III-R personality disorders (SCID-II). Part II: Multi-site test-retest reliability study. Journal of Personality Disorders, 9, 92-104. doi:10.1521/pedi.1995.9.2.92.

Flanagan, C. M. (2010). The case for needs in psychotherapy. Journal of Psychotherapy Integration, 20, 1-36. doi:10.1037/a0018815. 
Gagné, M. (2003). The role of autonomy support and autonomy orientation in prosocial behavior engagement. Motivation \& Emotion, 27, 199-223. doi:10.1023/A:1025007614869.

Gauthier, L., Guay, F., Senécal, C., \& Pierce, T. (2010). Women's depressive symptoms during the transition to motherhood: The role of competence, relatedness, and autonomy. Journal of Health Psychology, 15, 1145-1156. doi:10.1177/1359105310364170.

Germans, S., Van Heck, G. L., Masthoff, E. D., Trompenaars, F. J. W. M., Hodiamont, P. P. G. (2010). Diagnostic efficiency among psychiatric outpatients of a self-report version of a subset of screen items of the Structured Clinical Interview for DSM-IV-TR Personality Disorders (SCID-II). Psychological Assessment, 22, 945-952. doi:10.1037/a0021047.

Giesen-Bloo, J., Van Dyck, R., Spinhoven, P., Van Tilburg, W., Dirksen, C., Van Asselt, T., ... \& Arntz, A. (2006). Outpatient psychotherapy for borderline personality disorder: randomized trial of schema-focused therapy vs transference-focused psychotherapy. Archives of General Psychiatry, 63, 649658. doi:10.1001/archpsyc.63.6.649.

Hayes, A. F. (2013). Introduction to mediation, moderation, and conditional process analysis: A regression-based approach. New York, NY: Guilford Press.

Hsieh, S., McGrory, S., Leslie, F., Dawson, K., Ahmed, S., Butler, C. R., ... \& Hodges, J. R. (2015). The Mini-Addenbrooke's Cognitive Examination: a new assessment tool for dementia. Dementia and Geriatric Cognitive Disorders, 39, 1-11. doi:10.1159/000366040.

Hsieh, S., Schubert, S., Hoon, C., Mioshi, E., \& Hodges, J. R. (2013). Validation of the Addenbrooke's Cognitive Examination III in frontotemporal dementia and 
Alzheimer's disease. Dementia and Geriatric Cognitive Disorders, 36, 242-250. doi.org/10.1159/000351671.

Johnco, C., Knight, A., Tadic, D., \& Wuthrich, V. (2015). Psychometric properties of the Geriatric Anxiety Inventory (GAI) and its short-form (GAI-SF) in a clinical and non-clinical sample of older adults. International Psychogeriatrics, 27(7), 1089-1097. doi:10.1017/S1041610214001586

Johnston, C., Dorahy, M. J., Courtney, D., Bayles, T., \& O'Kane, M. (2009). Dysfunctional schema modes, childhood trauma and dissociation in borderline personality disorder. Journal of Behavior Therapy and Experimental Psychiatry, 40, 248-255. doi:10.1016/j.jbtep.2008.12.002.

Kashdan, T. B., Mishra, A., Breen, W. E., \& Froh, J. J. (2009). Gender differences in gratitude: Examining appraisals, narratives, the willingness to express emotions, and changes in psychological needs. Journal of Personality, 77, 691730. doi:10.1111/j.1467-6494.2009.00562.x.

Lobbestael, J., Arntz, A. and Sieswerda, S. (2005). Schema modes and childhood abuse in borderline and antisocial personality disorders. Journal of Behavior Therapy and Experimental Psychiatry, 36, 240-253. doi:10.1016/j.jbtep.2005.05.006.

Lobbestael, J., Van Vreeswijk, M.F, \& Arntz, A. (2008). An empirical test of schema mode conceptualizations in personality disorders. Behaviour Research and Therapy, 46, 854-860. doi:10.1521/pedi.2011.25.1.41.

Lockwood, G., \& Perris, P. (2012). A new look at core emotional needs. In M. van Vreeswijk, J. Broersen, \& M. Nadort (Eds.), The Wiley-Blackwell Handbook of Schema Therapy: Theory, Research, and Practice, (pp. 41-68), Hoboken, NJ: John Wiley \& Sons. doi:10.1002/9781119962830.ch3. 
Lu, Q., Uysal, A., \& Teo, I. (2011). Need satisfaction and catastrophizing: Explaining the relationship among emotional ambivalence, pain, and depressive symptoms. Journal of Health Psychology, 16, 819-827. doi:10.1177/1359105310392092.

Meyer, B., Enstrom, M. K., Harstveit, M., Bowles, D. P., \& Beevers, C. G. (2007). Happiness and despair on the catwalk: Need satisfaction, well-being, and personality adjustment among fashion models. The Journal of Positive Psychology, 2, 2-17. doi:10.1080/17439760601076635

Niemiec, C. P., Lynch, M. F., Vansteenkiste, M., Bernstein, J., Deci, E. L., \& Ryan, R. M. (2006). The antecedents and consequences of autonomous self-regulation for college: A self-determination theory perspective on socialization. Journal of Adolescence, 29, 761-775. doi: 10.1016/j.adolescence.2005.11.009

Ng, J. Y., Ntoumanis, N., Thøgersen-Ntoumani, C., Deci, E. L., Ryan, R. M., Duda, J. L., \& Williams, G. C. (2012). Self-determination theory applied to health contexts: A meta-analysis. Perspectives on Psychological Science, 7, 325-340. doi:10.1177/1745691612447309.

Pachana, N. A., Byrne, G. J., Siddle, H., Koloski, N., Harley, E., \& Arnold, E. (2006). Development and validation of the Geriatric Anxiety Inventory. International Psychogeriatrics, 19, 103. doi:10.1017/s1041610206003504.

Phillips, K., Brockman, R., Bailey, P. E. and Kneebone, I. I. (2017). Young Schema Questionnaire-Short Form Version 3 (YSQ-S3): Preliminary validation in older adults. Aging and Mental Health. Advance online publication. doi.org/10.1080/13607863.2017.1396579.

Sempertegui, G. A., Karreman, A., Arntz, A., \& Bekker, M. H. (2013). Schema therapy for borderline personality disorder: A comprehensive review of its 
empirical foundations, effectiveness and implementation possibilities. Clinical Psychology Review, 33, 426-447. doi.org/10.1016/j.cpr.2012.11.006.

Stiles, P. G., \& McGarrahan, J. F. (1998). The Geriatric Depression Scale: A comprehensive review. Journal of Clinical Geropsychology, 4(2), 89-110. doi: $10.1037 / \mathrm{t} 00930-000$

Talbot, D., Smith, E., Tomkins, A., Brockman, R., \& Simpson, S. (2015). Schema modes in eating disorders compared to a community sample. Journal of Eating Disorders, 3, 41. doi:10.1186/s40337-015-0082-y.

van Genderen, H., Rijkeboer, M., \& Arntz, A. (2012). Theoretical model. In M. van Vreeswijk, J. Broersen, \& M. Nadort (Eds.), The Wiley-Blackwell Handbook of Schema Therapy: Theory, Research, and Practice, (pp. 27-40). Hoboken, NJ: John Wiley \& Sons. doi:10.1002/9781119962830.ch2.

van Vreeswijk, M. F., Spinhoven, P., Eurelings-Bontekoe, E. H. M., \& Broersen, J. (2012). Changes in symptom severity, schemas and modes in heterogeneous psychiatric patient groups following short-term schema cognitive-behavioural group therapy: A naturalistic pre-treatment and post-treatment design in an outpatient clinic. Clinical Psychology \& Psychotherapy, 21, 29-38. doi:10.1002/cpp.1813.

van Wijk-Herbrink, M. F., Bernstein, D. P., Broers, N. J., Roelofs, J., Rijkeboer, M. M., \& Arntz, A. A. (2018). Internalizing and externalizing behaviors share a common predictor: The effects of early maladaptive schemas are mediated by coping responses and schema modes. Journal of Abnormal Child Psychology, 46, 907-920. doi:10.1007/s10802-017-0386-2.

Videler, A. C., Rossi, G., Schoevaars, M., van der Feltz-Cornelis, C. M., \& van Alphen, S. P. J. (2014). Effects of schema group therapy in older outpatients: A 
proof of concept study. International Psychogeriatrics, 26, 1709-1717. doi:10.1017/s1041610214001264.

Videler, A. C., van Alphen, S. P., van Royen, R. J., van der Feltz-Cornelis, C. M., Rossi, G., \& Arntz, A. (2017). Schema therapy for personality disorders in older adults: A multiple-baseline study. Aging \& Mental Health, 22, 738-747. doi:10.1080/13607863.2017.1318260.

Voderholzer, U., Schwartz, C., Thiel, N., Kuelz, A. K., Hartmann, A., Scheidt, C. E., ... \& Zeeck, A. (2014). A comparison of schemas, schema modes and childhood traumas in obsessive-compulsive disorder, chronic pain disorder and eating disorders. Psychopathology, 47, 24-31.

Yesavage, J. A., Brink, T. L., Rose, T. L., Lum, O., Huang, V., Adey, M., \& Leirer, V. O. (1982). Development and validation of a geriatric depression screening scale: a preliminary report. Journal of Psychiatric Research, 17, 37-49. doi:10.1016/0022-3956(82)90033-4.

Young, J. E. (1990). Cognitive therapy for personality disorders: A schema-focused approach. Sarasota, FL: Professional Resource Press.

Young, J. E. (2005). Young Schema Questionnaire - Short Form 3 (YSQ-S3). New York, NY: Cognitive Therapy Center.

Young, J. E., Atkinson, T., Arntz, A., Engels, I., \& Weishaar, M. (2005). The Young Atkinson mode inventory (YAMI-PM,1B). New York, NY: Schema Therapy Institute.

Young, J. E., Klosko, J. S., \& Weishaar, M. E. (2003). Schema therapy: A practitioner's guide. New York, NY: Guilford Press. 
Schema in older adults 